\title{
EDIFICAR SOBRE ROCA. FUNDAMENTOS CRISTIANOS DE LA FIDELIDAD*
}

DOI: https://doi.org/10.52039/seminarios.v52i179.674

Autor: Mons. D. Fernando Sebastián. Arzobispo de Pamplona y Tudela.
Constata la falta de fidelidad en sacerdotes jóvenes: ¿Qué hemos hecho mal? Hay que ayudar a que mantengan la fidelidad. El amor implica continuidad y permanencia pese a las dificultades. Fidelidad creadora. Sus enemigos: la transitoriedad. En el fondo, la perspectiva de un mundo sin Dios.

La fidelidad es de alguna manera la perfección o la consumación del amor, por lo cual la materia de nuestra reflexión en esta mañana es la preocupación central y la más alta aspiración de cualquier educador.

Esta preocupación se ha visto aumentada por la frecuencia con que algunos de nuestros sacerdotes jóvenes abandonan los compromisos adquiridos a los pocos años de haber sido ordenados.

Si con el tiempo de formación no conseguimos que los nuevos sacerdotes perseveren en su vida sacerdotal tenemos razón para preguntarnos qué es lo que no estamos haciendo bien.

La ordenación sacerdotal es una elección y consagración para toda la vida. Implica por tanto la capacidad de asumir compromisos estables y de mantenerlos durante toda la vida.

* Ponencia en el XXXIV Encuentro de Rectores y Formadores de Seminarios Mayores. Madrid, 16 al 18 de septiembre de 2005. 
Aun siendo conscientes de nuestras limitaciones, tenemos que preguntarnos sinceramente qué podemos hacer para ayudar a nuestros seminaristas y a los sacerdotes jóvenes a responder con fidelidad y estabilidad a la llamada del Señor y de la Iglesia.

Doy por supuesto que el tema de la fidelidad no es exclusivo de la educación para el ministerio sacerdotal. En realidad es un asunto que concierne a la educación en cuanto tal. Todos los hombres, varones y mujeres, estamos llamados a ser fieles. Fieles en nuestras promesas, en nuestros compromisos, en nuestras obligaciones, y especialmente fieles en nuestras relaciones de amor con las demás personas. En estos momentos nos ocupamos de la fidelidad en la vida sacerdotal, pero no es posible dejar de pensar en la necesidad de educar para la fidelidad en el marco general de la vida cristiana: fidelidad en la fe, fidelidad en las convicciones cristianas, fidelidad en el matrimonio y en el amor a la Iglesia.

\section{Qué es y cómo entender la fidelidad}

Llamamos fiel al que no abandona ni traiciona a una persona en momentos de dificultad. Fiel es también el que no engaña, el que mantiene los compromisos adquiridos o el amor prometido a una persona a lo largo del tiempo, a pesar de las dificultades que se puedan presentar.

La noción de fidelidad está íntimamente ligada a nuestra naturaleza temporal. Nuestros actos no son estables ni continuos, sino temporales y transitorios. Queremos, ofrecemos, prometemos amor eterno, pero luego tenemos que ocuparnos de otras cosas, cambian las circunstancias a nuestro alrededor y lo que nos parecía muy claro deja de serlo, o lo que veíamos sencillo se nos presenta difícil y complicado.

La movilidad del mundo en que vivimos, la naturaleza temporal y sucesiva de nuestros propios actos limitan la explicitud y permanencia de nuestros pensamientos, de nuestros afectos y sentimientos. Y la temporalidad lleva siempre la posibilidad del cambio y de la caducidad. Hoy puedo ver las cosas de una determinada manera con mucha claridad, y mañana las puedo ver de modo diferente. Hoy siento y me veo muy determinado en favor de algo y mañana puedo verlo con menos claridad y sentirme atraído por algo diferente. 
Frente a esta temporalidad de nuestros actos, es preciso afirmar la exigencia de continuidad que tiene el verdadero amor. El amor implica reconocimiento y afirmación del bien del otro sin limitaciones, de manera definitiva. Fiel es la persona que cuando la necesito siempre está. La fidelidad es esencial al amor y a la amistad. Fiel y amigo son dos palabras inseparables.

Del contraste entre la naturaleza temporal de nuestros actos y las exigencias de permanencia que nacen de la naturaleza misma del amor, surge la realidad de la fidelidad y su exigencia como coronamiento y perfección en el amor. Fidelidad es la permanencia del amor frente al paso del tiempo y la variedad de las circunstancias.

Visto así, podemos decir que la fidelidad es la capacidad de mantener la continuidad en el amor y en los compromisos adquiridos por encima de la temporalidad y de los cambios que puedan sobrevenir fuera o dentro de nosotros. La fidelidad es la continuidad de la presencia. La verdad y la continuidad del amor. A pesar de las dificultades.

La fidelidad es la permanencia en el amor frente al desgaste de la duración, de la temporalidad; también frente a los cambios de circunstancias, nuevos conocimientos, nuevas ideas, nuevas experiencias, nuevas necesidades. Cuando asumimos un compromiso no podemos adivinar qué dificultades o qué nuevas experiencias y necesidades vamos a experimentar en nosotros mismos dentro de unos años. El sujeto tiene que ser capaz de reafirmar sus propias elecciones ante las nuevas situaciones externas o internas. Para eso hace falta tener dentro de sí suficientes razones, motivaciones, estabilidad y fortaleza para recrear de nuevo los mismos afectos, los mismos compromisos, las mismas promesas. Teniendo en cuenta que estos cambios pueden ser conflictivos, excluyentes, dolorosos. Para mantener unas decisiones hay que renunciar a otras posibilidades incompatibles que pueden aparecer en nuestra vida, y hay que hacerlo sin traumas, sabiendo que es mejor la continuidad y la fidelidad que el desistimiento y la infidelidad. Porque la fidelidad da madurez, libertad, permanencia, supratemporalidad, capacidad para responder a la necesidad personal de continuidad, y a la necesidad también de continuidad de los seres queridos.

Por todo ello la fidelidad es bastante más que la simple duración. La fidelidad es siempre creadora, creadora de presencia renovada y victoriosa. Del interior del amor nace la exigencia de la duración, de la perma- 
nencia, de la perpetuidad. Es la condición absoluta de la persona la que reclama la permanencia del amor.

La fidelidad es la afirmación del carácter absoluto y definitivo del amor a pesar de la historicidad y la temporalidad de nuestra vida. En un momento determinado podemos hacer actos absolutos, con carácter definitivo, que luego necesitan ser renovados y mantenidos para poder alcanzar su pretensión de totalidad.

Amar es querer el bien de otra persona como parte del bien propio. El que ama a una persona lo hace porque considera que el ser y la vida de esa persona es un bien para él, forma parte de su vida y de su bien. Si se quiere el bien de una persona se ha de querer ilimitadamente, por todo el tiempo que es persona viva, por todo el tiempo que quiera y pueda vivir. Marcel dice, «Decirle a una persona "te amo", significa "quiero que existas y seas feliz para siempre". No podré ser feliz si no procuro que tú lo seas también y para siempre».

La fidelidad garantiza la continuidad en el amor y en las relaciones personales, y por eso mismo la continuidad en la vida personal. En cada acto de amor se contienen en germen todos los demás. Y cada nueva afirmación y desarrollo del amor en fidelidad asume y desarrolla los anteriores. Así se edifica en continuidad un misma persona que crece y amplia su mundo interior. En cambio, el contingentismo, la mutabilidad, destruye en un día lo que has podido edificar en años. La permanencia en el amor bueno, justo y verdadero, es fidelidad, es crecimiento. La persistencia en los amores injustos, dominantes, explotadores, es impenitencia y contumacia en el mal.

Toda fidelidad aspira a la incondicionalidad. Por eso afirma el valor absoluto de cada vida personal. De la persona que ama y de la persona amada, Del sujeto y del destinatario del amor. El amor fiel, el amor permanente barrunta el valor absoluto y el carácter eterno de la persona y apuesta por la inmortalidad. Por eso el amor fiel tiene siempre un carácter cercano a la experiencia religiosa.

La tendencia del amor a la perpetuidad nos descubre el deseo de la inmortalidad ("quiero vivir contigo para siempre", "quiero que tú vivas para siempre y seas siempre feliz"). Y por eso mismo descubre nuestra impotencia ("seré capaz de serte siempre fiel?"). Por eso el amor, la fidelidad es apertura a la fe y lleva a la invocación. La fidelidad suscita la plegaria, es mayor que lo que nosotros podemos ofrecer. El lenguaje de la 
fidelidad siempre es "que Dios me ayude a serte fiel", "que Dios te dé lo que yo no te puedo dar". El amor (en el matrimonio, en la consagración) acerca a la invocación, a la oración, a la fe en un Dios amoroso. El que entra en la dinámica del amor fiel, invoca la intervención de alguien que sostenga la vida de la persona querida y que nos ayuda a amarla fielmente por encima de todas las eventualidades.

La exigencia de la fidelidad como verdad del amor es patente en nuestras relaciones con Dios. La bondad de Dios permanece para siempre. Si Dios es amable hoy lo es para siempre, pase lo que pase. El primer momento del amor verdadero requiere ser renovado, mantenido, alimentado, ejercitado permanentemente, a lo largo de toda la vida, superando la caducidad del tiempo.

Es más, aunque nuestros actos se produzcan siempre en el tiempo, nuestras relaciones con Dios no pueden ser correctas si no tienen esa aspiración a la totalidad. No podemos amar a Dios como Bien absoluto sin amarlo con un amor también absoluto, que implica la voluntad y el compromiso de mantenerlo a lo largo de la vida, a pesar de la sucesión y cambios de situaciones y circunstancias.

$\mathrm{Y}$ algo semejante ocurre con las personas. En la medida en que una persona es reconocida como algo absoluto no podemos elegirla, amarla como le corresponde, sin que nuestro amor implique la voluntad de mantenerlo a lo largo del tiempo, por encima de todos los cambios previsibles y posibles.

La fidelidad es la dimensión absoluta de nuestros actos concretos y temporales, el acceso a la eternidad desde las estrecheces de la temporalidad. Si cada uno es hijo de sus acciones, la fidelidad en el amor nos permite superar la temporalidad y entrar en una dimensión de supratemporalidad y casi de eternidad. Los santos viven establemente en el amor..

Los votos, las promesas, los compromisos, el mismo acto de fe en Dios, son actos que se realizan en un momento determinado de la vida, pero, para ser auténticos, en su temporalidad llevan la aspiración de la estabilidad, de la duración. La fidelidad es la capacidad de conseguir en el tiempo la estabilidad y la eternidad de nuestra vida espiritual.

El Dios todopoderoso no puede ser amado por nosotros de otra manera. Los bienes absolutos no pueden ser amados más que absolutamente. El que mira hacia atrás no es apto para el Reino de los Cielos (Cf Lc 9, 61). 


\section{Los enemigos de la fidelidad}

Podemos enumerar como enemigos de la fidelidad todos aquellos elementos o factores que intervienen en nuestra vida que favorecen la transitoriedad, desde el punto de vista intelectual, o desde el punto de vista afectivo, y más profundamente en el campo de lo volitivo, el campo de las decisiones, de los deseos profundos que rigen de verdad nuestra vida y seleccionan nuestras verdaderas aspiraciones.

Son enemigos de la fidelidad, la simple duración en el tiempo, la pasividad, la rutina, la falta de iniciativa, el acomodamiento a las circunstancias, el temor a las dificultades. Si no renovamos las motivaciones originales, nuestras convicciones se debilitan y crecen otras, como consecuencia de las nuevas experiencias de vida, que pueden acabar sustituyendo y aun anulando las anteriores.

Más profundamente que los factores meramente psicológicos, hoy tenemos que tener en cuenta que vivimos en una cultura de la transitoriedad. El consumismo nos acostumbra a vivir en la provisionalidad, en la lógica del "usar y tirar". En el fondo hay una motivación de falso amor a sí mismo que nos lleva a amar falsamente a las personas no para SU bien, sino para NUESTRO bien, bien superficial, sensible, emotivo, efímero. No es sólo una cultura de la transitoriedad sino una cultura del egoísmo, del bien-estar, del estar bien a costa de los demás. No queremos a las personas para hacerles el bien mientras vivan, o para que vivan, sino que las queremos mientras nos caen bien, nos encontramos bien con ellas, mientras podemos esperar de ellas algo agradable. En el matrimonio, en la vida sacerdotal, es un peligro apoyarse en razones de conveniencia o de sentimientos o de pequeñas ambiciones, porque estas razones no pueden alimentar un amor permanente, ni siquiera un amor verdadero. Es un amor falso que utiliza a una persona para amarse o complacerse a sí mismo. Y en el caso del sacerdocio se utiliza un "status" un "munus" como pedestal y fuente de gratificación más que como consecuencia de un verdadero amor, a Jesucristo, a Dios, a la Iglesia, a los hermanos.

Como consecuencia de esta visión de la vida (digamos, de este sometimiento al egoísmo original), hoy no se ve la infidelidad como una falta, sino como una conducta normal. Nuestra sociedad está aceptando como algo normal que una persona desista de sus compromisos cuando le resul- 
tan especialmente difíciles o ha perdido las motivaciones que le impulsaron a adquirirlos. En el matrimonio se ve normal que si el amor desaparece, si surgen dificultades de convivencia, o se presenta otro amor mejor, los compromisos adquiridos cedan su lugar a otros nuevos. Y se ve también con cierta normalidad que los compromisos religiosos se disuelvan cuando resultan penosos. (Una cosa es que resulten perjudiciales por una decisión equivocada, otra cosa es que resulten penosos y exigentes, pero accesibles con la ayuda normal de Dios y de los medios que El pone a nuestra disposición).

En realidad estamos perdiendo la noción misma de compromiso a perpetuidad. La perpetuidad se ve como algo imposible para el ser humano. La gente se casa sin la voluntad de permanecer juntos durante toda la vida. Viviremos mientras nos queramos, mientras vayan las cosas bien, hasta que no surja otra cosa mejor. En realidad ya no tenemos intención de amar con una exigencia de estabilidad y permanencia. Ahora vivimos así, luego ya veremos. En el fondo de todo sigue perviviendo la perspectiva autista. "Te querré mientras me venga bien, mientras me seas útil" Es duro decirlo, pero es una actitud frecuente que sólo la conversión a Dios es capaz de modificar definitivamente.

En esta nueva el valor de la fidelidad se debilita. Y resulta casi imposible. Si no hay voluntad de permanencia, no se puede hablar ya de fidelidad como una pretensión y un acto positivo de libertad. Podremos hablar de duración, como algo fáctico. De hecho llevamos juntos tres o veinte años. Pero si no existe el compromiso y la voluntad de perpetuidad, no se puede hablar de fidelidad. Fidelidad es la continuidad de la voluntad en el amor, en los compromisos, en la relación de benevolencia con una persona. La continuidad con una decisión adoptada con voluntad de permanencia y totalidad.

La cultura actual nos acostumbra a necesitar muchas cosas efímeras, a cambiar con frecuencia, a ser inestables afectivamente. Quienes se dejan configurar por la cultura de la publicidad y del consumo no pueden soportar estar mucho tiempo en el mismo sitio, con el mismo trabajo, con las mismas personas. Necesitan la novedad, la excitación, la sorpresa y hasta la inseguridad del cambio.

En nuestra cultura la fidelidad está amenazada y negada por otras muchas cosas. El hombre moderno tiene una experiencia intensa de la variabilidad de las cosas que le asusta el comprometerse establemente en 
cualquier cosa. Cambias las circunstancias, cambian los gustos, las conveniencias, no tiene sentido atarse para siempre a un modo de vida, a una profesión, a una persona determinada. Siente necesidad de reservarse la posibilidad de cambiar, aun a costa de no experimentar nada a fondo. La libertad es más disponibilidad que decisión. Y más profundamente se vive más como capacidad de felicidad personal que como capacidad de responder a nadie o comprometerse definitivamente con el bien de nadie.

A la vez nos acostumbramos a remediar las dificultades cambiando lo que haga falta. Nos cuesta trabajo soportar dificultades, superar situaciones, corregir o soportar deficiencias. Resulta más cómodo, menos exigente, más expedito cambiar. El cambio es el gran aliado de la comodidad, del no esfuerzo, de la completa libertad. Vivimos en la cultura del cambio. Nos mantenemos vivos cambiando de lugar, de amigos, de trabajo, en vez de ahondar en las razones y en las aspiraciones de nuestra vida. Detrás de todo esto está también la perspectiva de un mundo sin Dios donde no hay nada ni nadie digno de un amor total y perpetuo, capaz de alimentar nuestro interés por la vida perpetuamente.

Para llegar al fondo de la cuestión tenemos que reconocer que en nuestra cultura se reconoce el valor central de la libertad, pero con una idea de libertad que excluye frontalmente lo que estamos diciendo a propósito de la fidelidad. La filosofía existencialista ha socializado una idea de libertad entendida como "disponibilidad permanente". Cuando un joven nos dice que quiere ser libre, suele querer decir que él quiere mantener la capacidad de hacer en cada momento lo que le parezca mejor. En esta visión de las cosas libertad es sinónimo de provisionalidad. Todos los compromisos son provisionales, revisables, condicionados. Se cuenta con la temporalidad y se acepta como un bien, o por lo menos como una fatalidad.

En el fondo de esta concepción hay un compromiso definitivo que muchas veces permanece oculto, es el compromiso del amor a sí mismo. La libertad consiste en defender por encima de todo la capacidad de hacer en cada momento lo que me parezca mejor. Así el sujeto se autoconfina en la temporalidad, en la caducidad del gusto, del placer, de la moda, de lo que nos venga mejor en cada momento, de lo efímero. Son las fuentes del hastío y del "tedium vitae".

Nuestra sociedad no educa para edificar casas sólidas que resistan los embates del tiempo. Somos nómadas del sentimiento, nómadas de la libertad, de una libertad nunca entregada ni comprometida del todo, una liber- 
tad sin raíces que se quiere mantener siempre abierta, siempre disponible, en realidad una libertad narcisista, enamorada de sí misma.

Sabiéndolo o sin saberlo, un cierto estilo de educación, muy frecuente entre nosotros, favorece este tipo de personalidad, inquieta, vulnerable, poco preparada para soportar contratiempos ni superar dificultades, necesitada de muchas cosas, inestables, poco resistentes al desgaste del tiempo. Se trata en el fondo de personalidades poco creativas, que necesitan la ayuda de estímulos exteriores continuamente renovados para mantenerse activos y vivir a gusto. La educación de la condescendencia, del halago, de la no exigencia, del acumulamiento de dones y halagos favorece el crecimiento de estas personalidades que apoyan su vida en los bienes que vienen temporales y sucesivos, acumulados, que vienen de fuera, más que los bienes permanentes que uno encuentra en la purificación y fortalecimiento de los propios afectos.

Por eso todo aquello que implica un compromiso de por vida asusta, parece abusivo, contrario a una libertad entendida de otra manera, aburrido, perjudicial, y a fin de cuentas imposible. La fidelidad se percibe como cautividad, como renuncia a la libertad y a la felicidad.

En resumen, podemos decir que enemigos de la fidelidad son:

- el error en las motivaciones. Apoyarse en motivaciones efímeras produce amores efímeros. (La belleza, el placer, el éxito, la complacencia de alguien)

- confundir el amor con un sentimiento, con una emoción. El amor romántico confunde el amor con el sentimiento, con las emociones. Estas son pasajeras, involuntarias. El amor es libertad, elección, y decisión.

Confundir amor con complacencia, la complacencia es amor de sí mismo, no amor del otro.

Incapacidad de sufrir y soportar contradicciones, conflictos, renuncias, sacrificios. El amor no siempre trae satisfacciones, también exige sacrificios, renuncias. Es más, estamos hechos de tal manera que sólo el sufrimiento y las renuncias (la abnegación, la ascética) nos obliga a clarificar y fortalecer nuestras decisiones superando las falsas justificaciones y apoyándonos cada vez más claramente en las motivaciones verdaderas y permanentes.

Buscar ventajas y provechos en el amor. El amor se justifica por sí mismo. No busca ni necesita frutos, ventajas, retribuciones. Quien ama a 
una persona para conseguir un bien de ella, no ama a la persona, sino que ama al bien que espera de ella. En definitiva se ama a sí mismo.

\section{Visión cristiana de la fidelidad}

Podemos decir que la fidelidad es un descubrimiento religioso. La fidelidad no es creatura de este mundo. Nosotros solos no hubiéramos podido descubrir ni alcanzar la verdadera fidelidad. Si todas nuestras cosas son temporales y pasajeras, por qué no iba a serlo también el amor? La fidelidad es una cualidad del amor de Dios. Conocemos la verdadera fidelidad cuando Dios nos manifiesta su amor, un amor gratuito y fiel, irrevocable, porque está fundado en su bondad, en su querer amarnos, y no en nuestros méritos. Un amor que origina nuestro ser y nuestra bondad, misericordioso, que llegó hasta el final.

La Sagrada Escritura habla profusamente de la fidelidad de Dios. La fidelidad es la confirmación del amor de Dios. Dios nos ama con un amor misericordioso y fiel, un amor que no traiciona, que no desiste, que se afirma por encima de nuestros pecados. Un amor más fuerte que la muerte. Dios ha sido capaz de venir hasta nosotros y morir por nosotros. Quién podrá privarnos de este amor irrevocable de Dios? Vale la pena leer las expresiones entusiastas de Pablo en el capítulo VIII ${ }^{\circ}$ de Romanos.

La alabanza de la fidelidad de Dios es constante en los Salmos. Véanse p. e. los salmos 99 y 116: El amor de Dios es irrevocable, su fidelidad es eterna.

Jesucristo, el Hijo de Dios, es el Hijo fiel, fiel a Dios y fiel a nosotros, a la misión recibida del Padre. Jesús aparece como el Hijo que ama al Padre, que cumple su voluntad, y se mantiene en ella a pesar de todas las dificultades, por encima de la misma muerte. La fidelidad de Jesús en la Cruz, en la soledad de la muerte, ante el abandono: lo que Él vive desde su humanidad como un abandono del Padre, esa fidelidad consumada es la esencia de la religión cristiana, el restablecimiento de la Alianza nueva e irrevocable, por parte de Dios y por parte del hombre, la fuente y la raíz de nuestra redención, el principio de la nueva humanidad. Este amor fiel de Jesús es la roca firme de nuestra vida, de nuestra autoestima, de la seguridad de nuestra existencia y de nuestra capacidad de amar, a pesar de 
todos los pesares. Es la victoria del amor sobre el egoísmo, de la vida sobre la muerte.

A este amor fiel de Dios y de nuestro salvador responde la Iglesia con un amor fiel, es el amor de María, la Virgen fiel, el amor de los mártires y de los santos. De este modo la fidelidad queda vinculada al amor de Dios, a la fe, a la obediencia y sobre todo a la respuesta de amor que el amor de Dios pide de nosotros. La vida del cristiano es la historia de un amor fiel que nace, se desarrolla a lo largo de toda la vida, se afirma y se reafirma por encima de todas las dificultades, las oscuridades, los escándalos y sufrimientos.

Esta respuesta de amor fiel es el principio de la vida cristiana, de la vida teologal, iniciada en el bautismo. El bautizado comparte la muerte de Cristo porque comparte la obediencia a Dios y el amor al Padre de forma irrevocable, a pesar de todos los pesares, más fuerte que la muerte, un amor llamado a mantenerse, a reafirmarse, a crecer hasta el encuentro final y dichoso, más allá de la muerte. El modelo de toda vida cristiana son los mártires. Todo cristiano es un mártir en potencia. Hay que llegar hasta esta adhesión a Cristo y al Padre con El más fuerte que la muerte. Esta es la verdadera garantía de la fidelidad. El bautismo nos sitúa en la experiencia del "amor más fuerte que la muerte", por eso comprende toda la vida, por eso bautizado previve de alguna manera su propia muerte con Jesús en amor y confianza, supera el tiempo, vence el poder del demonio y se sitúa en los umbrales de la eternidad, en la anticipación de la resurrección, en la consumación del amor. La fidelidad es simplemente el despliegue de esa consagración total al Señor que vive dentro de la significación y la eficacia verdadera de nuestro bautismo. Nuestra fidelidad es la revivencia de la fidelidad de Jesús en nosotros.

En el caso del sacerdote la fidelidad está además requerida y configurada por la respuesta a la elección de Dios, a la llamada de la Iglesia, a las exigencias concretas de una misión y de un servicio que abarca la vida entera. Quien recibe por amor la llamada y la misión del ministerio sacerdotal, se ve requerido a responder con una disposición absoluta que debe ser renovada fielmente a lo largo de la vida, en todo momento y contra todas las dificultades.

Cualquier vocación, cualquier proyecto personal, en el matrimonio como en el ministerio sacerdotal, tiene que asentarse sobre los cimientos de una vida cristiana vivida con intensidad, con hondura, con verdadero 
entusiasmo, una vida cristiana lo más personalizada posible, con voluntariedad y convicciones, fundada en la seguridad del amor de Dios en Cristo y en la respuesta de un amor incondicional, libre y convencido, confirmado con las obras, a la persona de Jesucristo, un amor que sea la clave de la comprensión y de la configuración de la propia vida, con hondura, con verdad, con eficiencia, con alegría y generosidad. Con una inmensa gratitud y una sincera humildad.

\section{Educación para la fidelidad}

El secreto de toda educación es el de favorecer convicciones que motiven y configuren el comportamiento de las personas. ¿Cómo fomentar motivaciones estables que sostengan la fidelidad en los compromisos adquiridos?

La respuesta es sencilla. En la educación de nuestros seminaristas tenemos que buscar motivaciones religiosas, lo más firmes y estables que sea posible, capaces de justificar la perseverancia en los compromisos adquiridos a lo largo de toda la vida.

Esto quiere decir que hay que descartar motivaciones superficiales, ocasionales, poco realistas, aunque se revistan de mucha generosidad. No hablemos de las vocaciones fundadas en los deseos de otra persona, los padres, los educadores, el ambiente donde se vive. Parece extraño, pero estos casos todavía se pueden dar en ciertos ambientes. Más peligro hay de que las razones verdaderas de una vocación se sustituyan por razones de tipo secularista y de liderazgo social, como "cambiar el mundo", "el apostolado en el mundo obrero", "trabajar por la promoción de los pobres", "hacer un mundo más justo", etc. Pueden presentarse también motivaciones espiritualistas, como "convertir las almas", imitar la vida de algún personaje del momento, ser santo (se entiende con una santidad reconocida y aplaudida). Todas ellas son razones aparentemente positivas, que puedan significar una ayuda en determinados momentos de la vida, pero que no resultan suficientes para justificar una decisión permanente, capaz de reafirmarse ante nuevas circunstancias a lo largo de la vida entera. Razones que no son las motivaciones estrictamente específicas y ver- 
daderamente permanentes y justificatorias de una vida del todo entregada al servicio ministerial por amor a Jesucristo, por valoración de su misión, y entrega al bien de los hermanos.

No podemos olvidar que la mayor parte de los jóvenes de ahora tienen caracteres de hijos únicos, mimados, consentidos, sin experiencia de renuncias ni de sufrimientos, con la idea de que el amor consiste en recibir toda clase de agasajos, sin exigencias de correspondencia. Tienen experiencia de ser queridos con un amor que da muchos gustos pero que no requiere una respuesta, una correspondencia. Así el joven del amor condescendiente aprende a amarse a sí mismo, pero no aprende a amar de verdad a los demás.

Esta situación dificulta la formación de los candidatos al sacerdocio. Muchas veces en la formación de los seminaristas hay que rectificar formas de ser adquiridas, desarrollar hábitos no favorecidos en la educación familiar. En concreto el ejercicio RESPONSABLE de la libertad, la austeridad de vida, la laboriosidad, la generosidad. Todo ello es necesario para aprender a amar con un amor verdadero, no ególatra, y con un amor permanente y fiel, capaz de reafirmarse por encima de los cambios y de las dificultades.

El candidato debe aceptar el sacerdocio con una conciencia clara de ser llamado por Dios, conciencia clara de que la dedicación al ministerio es la forma concreta de responder al amor de Dios, de seguir a Jesucristo, y por eso mismo de justificar su vida y caminar hacia la perfección y la salvación de la vida eterna.

La vocación al ministerio requiere un amor sincero, convencido, efectivo, dominante y configurante hacia la persona de Jesús, su vida, sus enseñanzas, su misión, su presencia y su actuación en el mundo. Una convicción sin fisuras de la importancia de la fe en Jesús para el bien de las personas ahora mismo, en su realización personal y en su salvación eterna. Y desde esta identificación apasionada con la persona de Jesús, un amor verdaderamente adorante, religioso, obediente, confiado, FILIAL, hacia el Padre. Un amor probado, fortalecido con renuncias efectivas, al ambiente, a los bienes de este mundo, a los proyectos de este mundo, a otros amores posibles. La renuncia, la abnegación, la ascética es el reverso del amor, la prueba y la efectividad del amor, el golpe que hace crecer la llama y el fuego del amor, lo que nos obliga a crecer en el amor verdadero y purificarnos del egoísmo que renace permanentemente en nosotros. 
Conviene desarrollar una formulación precisa y una alta valoración de lo que es la substancia del ministerio sacerdotal, que vale y está presente siempre, por mucho que cambien las circunstancias y los tiempos. Ser ministros de Jesús, en comunión con la Iglesia, para anunciar su palabra, presidir la eucaristía y conceder su perdón. Sin necesidad de buscar la autoestima y la autojustificación de la vida en otras cosas, la estima social, las obras sociales, los frutos y los éxitos, los cargos, la alabanza de los superiores, etc.

Evitando fundamentalismos y simplificaciones, no podemos dejar de tener en cuenta la conexión entre la respuesta a la vocación y la salvación eterna. Es evidente que por la misericordia de Dios siempre y todo podemos alcanzar la salvación. Pero también es cierto que la negación voluntaria a una posible vocación conocida con suficiente claridad, puede ser una quiebra en la respuesta a Dios que debilite la vida sobrenatural del creyente, mientras no haya un acto de reconocimiento y de rectificación.

Con estas motivaciones de orden teologal, el seminarista debe desarrollar la estima del ministerio sacerdotal en aquello que verdaderamente es causa del valor de esta vocación. El ministerio sacerdotal no siempre nos proporciona la estima de la gente, ni la placidez de una vida tranquila, ni es seguro que vayamos a conseguir muchos éxitos pastorales. La vida eclesial no siempre es una vida fraternal ni alegre. En los años de una vida sacerdotal hay tiempo para todo, para temporadas en las que vivimos tranquilos y a gusto, y temporadas también en las que nos toca sufrir críticas, incomodidades, privaciones, disgustos. $Y$ tenemos que tener razones para pasar por todo con tranquilidad y con gusto.

Los futuros sacerdotes tienen que ser capaces de vivir felices a pesar de sus experiencias de irrelevancia social, sensación de fracaso e inutilidad, a pesar de los conflictos, envidias e incomprensiones, la hostilidad del ambiente, las muchas seducciones que nos pueden golpear en diferentes momentos y situaciones de la vida.

La vida de un Seminario no puede ser una vida de facilidades y condescendencias. Nuestros seminaristas necesitan crecer en un clima de mucha piedad, de un amor entusiasta hacia el Señor, un gran amor y una gran valoración del ser profundo y verdadero de la Iglesia, un gran amor hacia los hermanos a quienes tienen que servir y ayudar en el nombre y con el estilo del Señor. Con María y como María, con los Santos y como los Santos. 
Veamos brevemente las exigencias más directas de una buena educación para la fidelidad.

AMAR. Todo en la vida espiritual es fruto del amor. Pero aquí nos referimos a un amor muy concreto. Como primer fundamento de la fidelidad tenemos que reconocer la autenticidad del amor. Es preciso que la respuesta a la vocación sea inculcada y sea vivida como una respuesta de amor al amor de Dios que nos 1lama, al amor de Cristo que nos llamó a colaborar en su misión, una respuesta de amor a los hermanos que necesitan nuestro ministerio para conocer y alcanzar la salvación. Este amor no puede ser un amor genérico, sino un amor personal y directo con Cristo y con Dios que dé descanso y alegría. Un amor que sea una verdadera convivencia, una verdadera amistad con el Señor, capaz de proporcionar la alegría y el gozo de la convivencia sin el cual no se puede vivir. Un amor identificado con uno mismo que sea el apoyo real de nuestra vida, la raíz de nuestras motivaciones, el premio suficiente de todos nuestros esfuerzos. El sacerdote necesita sentirse acompañado, querido, por el Señor, por la Virgen María, por los santos, y por las Personas de la Trinidad santa, para sentirse siempre feliz, sin necesidad de otras compensaciones ni éxitos de ninguna clase. Invitado a responder con su amor renovado cada día. La fidelidad es la pervivencia en el amor. Este amor no debe ser confundido con el agrado, con el fervor sensible, con la alegría que en tiempos de fervor puede producir este amor. Ni mucho menos con la estima social que el hecho del sacerdocio puede acarrear, incluso hoy, en ciertos ambientes. El amor tiene que ser consecuencia del conocimiento, de la adoración, de la estima. Amar es ofrecer la vida, adherirse a la voluntad, asumir la misión de Jesucristo como razón de la propia vida, con entusiasmo, con ilusión, con alegría, con una claridad que crece con la vida, por el estudio, por la oración, por la experiencia misma del amor y del servicio que se resuelve en nuevas experiencias de amor y de convivencia con el Señor. En eso, sin necesidad de otras compensaciones, está la justificación y la felicidad de la vida. Me acuesto satisfecho porque he vivido con Jesús y para Jesús, independientemente de que me alaben o no, de que obtenga fruto o no. La tristeza, la decepción es signo de falta de autenticidad en las motivaciones. Una vida triste es una vida donde ya ha desaparecido el amor verdadero y quedan solo las apariencias, el caparazón, la ficción de la vida verdadera. 
ORAR. La fidelidad es un don. Nadie puede garantizar lo que va a hacer mañana. Cada día hay que pedir a Dios con humildad la perseverancia, la fortaleza y el amor suficiente para corresponder con ilusión a los dones recibidos. El "No nos dejes caer en la tentación" es también no nos dejes caer en la tentación del tedio, del cansancio, del desaliento, de la infidelidad. La perseverancia no está al alcance de nadie, sino que es un don de Dios que tenemos que pedir con amor, humildad y confianza. El simple pasar el tiempo puede desgastar convicciones y motivaciones. Y más si surgen otras diferentes. Es preciso mantener las convicciones y las motivaciones bien actualizadas con la oración y el estudio. La oración y el estudio se alimentan mutuamente en la vida del cristiano y en la vida del sacerdote, de esta conjunción nacen las convicciones y se fortalecen las motivaciones, actualizadas, renovadas, fortalecidas. Para un candidato al sacerdocio, la oración y el estudio (sobre todo de la Escriura) son el acceso al encuentro personal con el Señor, la justificación de su vida, la fuente profunda de su alegría, su primera compañía.

LA PENITENCIA. En la pedagogía de la fidelidad, la penitencia es necesaria en un doble sentido. Cualquiera de nosotros puede sufrir un desfallecimiento, puede fallar en la fidelidad en un momento determinado. En este caso la fidelidad de Dios sigue ante nosotros reclamando y haciendo posible el arrepentimiento y la renovación de un amor renacido con la humildad y el fervor de los arrepentidos. El perdón es un desbordamiento del amor, una prueba y un fruto de la fidelidad de Dios, una razón de más para renovar nuestra fidelidad. Con esta penitencia es preciso desarrollar también la penitencia de la tibieza, de las pequeñas infidelidades, de los pecados veniales, de las componendas. Todos sufrimos la tentación de la mediocridad, del acomodo, de la renuncia a los grandes ideales. La tibieza mina el vigor de la fidelidad y prepara la infidelidad. Es preciso revisarse con frecuencia, recuperar el vigor inicial, luchar continuamente contra la tibieza y la mediocridad. Un plan de vida realista, bien cumplido, y una asistencia espiritual estricta es la mejor ayuda en este camino de fidelidad y penitencia.

COMUNIÓN ECLESIAL. Las personas más fuertes necesitan la ayuda de una comunidad, grande o pequeña, en la que somos comprendidos, aceptados, valorados. Esta primera comunidad de referencia para el 
sacerdote tiene que ser su Iglesia particular, el Obispo, otros hermanos sacerdotes, el presbiterio diocesano. También los fieles ayudan al sacerdote, pero su presencia y su comprensión no suele ser tan profunda ni tan estable como la convivencia de los hermanos sacerdotes. No me refiero sólo a las ayudas concretas y ocasionales, sino al sentimiento permanente y difuso de estar viviendo entre hermanos, rodeado de comprensión y de afecto, seguro de ser comprendido y ayudado en cualquier circunstancia de la vida. Hoy el sacerdote no puede pretender ser comprendido y valorado en los ambientes seculares de nuestra sociedad. Si acaso será valorado en la medida en que se seculariza él mismo en su vida y en sus costumbres. Necesitamos vivir en una sociedad que nos valore precisamente por ser sacerdotes fieles. Y esta sociedad es sólo la sociedad de los fieles, la Iglesia. Existe el peligro de confundir la Iglesia con el pequeño grupo de los que piensan como uno mismo, el grupo de los de siempre, de los amigos, de los de la misma línea, etc. Los seminaristas tienen que aprender a vivir con gratitud y alegría en la Iglesia DE JESÚS, y por ser la Iglesia de Jesús, la Iglesia de su presencia, de su palabra, de sus sacramentos, de sus santos, de su perdón, vivir feliz y a gusto a pesar de las adversidades y de los sufrimientos que tengamos que soportar, por nuestras limitaciones, por las limitaciones de los demás, por las tensiones y por tantas otras cosas que lleva consigo la convivencia con otras personas también en la Iglesia. Es importante una visión de fe de la Iglesia y una aceptación madura de las limitaciones de los hombres. Esta visión de fe y este amor agradecido les ayudará a sufrir con paciencia y a renovar el amor y los buenos sentimientos hacia las personas concretas en las que se concreta la presencia real de la Iglesia junto a él. Detrás de ellas está Jesús, su presencia, su gracia, sus dones, su llamada y su servicio.

ABNEGACIÓN Y DESPRENDIMIENTO. La vida sacerdotal puede resultar dura en algunos momentos. Nuestros jóvenes tienen que ser capaces de renunciar a cosas, a personas, a gustos y proyectos. Renunciar no absurdamente por el gusto de renunciar, sino renunciar para concentrarse en lo que es el centro de sus aspiraciones, el conocimiento y el amor a Jesús, la plena disponibilidad y dedicación, la autoexigencia en el trabajo, en servicio, en el aprovechamiento del tiempo, en el rendimiento de todas sus posibilidades al servicio de la misión encomendada y aceptada, etc.etc. El sacerdote tiene que saber vivir en soledad. Unas veces esta sole- 
dad se lleva con facilidad, pero en otros momentos puede resultar penosa y difícil de soportar. A esta sensación de soledad se puede sumar la falta de estima social que en la actualidad tiene que soportar el sacerdote. En algún momento el joven sacerdote puede sentir la sensación de no ser nadie, de no estar hacer nada importante. A estas impresiones puede añadirse la sensación de inutilidad y fracaso al no obtener frutos visibles y cuantificables. Contra todo esto, el sacerdote debe cultivar la estima de su ministerio, la confianza en la importancia y efectividad de lo que hace, como consecuencia de la valoración de la obra del Señor. Es muy importante que el sacerdote aprenda a justificar su existencia por lo que hace, en la oscuridad y seguridad de la fe, sintiéndose compensado por el hecho mismo de ser y actuar como apóstol de Jesús, sin necesidad de recoger muestras sensibles del valor o de la eficacia de su ministerio. La razón de la fidelidad no está en la eficacia de nuestra vida, sino en el amor fiel de Dios, en la entrega definitiva de Jesús, a la que nosotros hemos sido invitados. El seminarista, sobre todo en los primeros años del seminario, tiene que experimentar y superar el dolor de ciertas rupturas, privaciones, renuncias. Es la única forma de que aclare y profundice sus convicciones, de que lleguen a ser operativas y determinantes en su vida. Las renuncias de la vida adulta tienen que estar "ensayadas" en el tiempo de formación. Como ocurre en la vida deportiva. Sin renuncias, sin privaciones, sin ascética no hay clarificación ni arraigo de las convicciones, no hay sobre todo ejercicio de la libertad en la reafirmación de las decisiones adoptadas. En calcular y dosificar estas pequeñas pruebas tiene que estar la prudencia y el acierto de los buenos educadores. Desde luego, está claro que la pedagogía de la condescendencia, del evitar lo que cuesta, no prepara para la vida real del futuro.

Estas reflexiones nos pueden ayudar a descubrir lo importante que es la buena orientación de nuestros candidatos actuales para su vida de mañana. Esta es hoy una gran responsabilidad para todos nosotros. Una gran responsabilidad y un gran deseo. Oremos al Señor, pidámosle que nos ayude a transmitirles el amor y la paciencia y la fortaleza invencible de la Iglesia fiel, la Iglesia de María, de los Apóstoles, de los mártires. Pidamos al Señor que se cumpla en ellos su palabra: "El que escucha mis palabras y las pone en práctica es como el hombre prudente que edificó su casa sobre roca" (Mt 7, 24). 